\title{
Lung cancer in which the hypothesis of multi-step progression is confirmed by array-CGH results: A case report
}

\author{
DANIELA BETTIO ${ }^{1}$, ANNA VENCI ${ }^{1}$, VALENTINA ACHILLE ${ }^{1}$, MARCO ALLOISIO $^{2}$ and ARMANDO SANTORO ${ }^{3}$ \\ ${ }^{1}$ Cytogenetic and Medical Genetic Laboratory, Operative Unit of Clinical Investigations; ${ }^{2}$ Department of Thoracic Surgery; \\ ${ }^{3}$ Department of Oncology and Hematology, Humanitas Cancer Center, \\ Humanitas Clinical and Research Center, Milan I-20089, Italy
}

Received February 19, 2015; Accepted September 28, 2015

DOI: $10.3892 / \mathrm{etm} .2015 .2870$

\begin{abstract}
The pathogenesis of lung cancer has not been fully elucidated and biological markers acting as predictors of tumor evolution and aggressiveness remain unidentified. The multi-step hypothesis, suggesting a progression from adenomatous hyperplasia $(\mathrm{AAH})$ to adenocarcinoma (AC) through bronchioalveolar carcinoma (BAC), was highlighted in a previous cytogenetic study performed in a single case. The present study reports the results of an array-comparative genomic hybridization (a-CGH) analysis performed on the DNA obtained from the previously reported case that presented $\mathrm{AAH}, \mathrm{BAC}$ and $\mathrm{AC}$ in one lung. The a-CGH results confirm and support the previous cytogenetic observations with new data, clearly supporting the hypothesis of a multi-step carcinogenic process in the lung.
\end{abstract}

\section{Introduction}

The mechanisms underlying lung cancer pathogenesis and progression remain under investigation. Ground-glass opacity (GGO) lesions, increasingly detected by computed tomography (CT) scanning, can be classified as adenomatous hyperplasia (AAH), bronchioalveolar carcinoma (BAC) or adenocarcinoma (AC). Several studies have suggested that $\mathrm{AAH}$, frequently found in tissue surrounding lung $\mathrm{AC}$, might be a forerunner in the development of AC. Moreover, an increasing genetic complexity associated with lung cancer progression has been demonstrated by means of loss of heterozygosity, fluorescence in situ hybridization, microarrays and

Correspondence to: Dr Daniela Bettio, Cytogenetic and Medical Genetic Laboratory, Operative Unit of Clinical Investigations, Humanitas Clinical and Research Center, Via Manzoni 56, Rozzano, Milan I-20089, Italy

E-mail: daniela.bettio@humanitas.it

Key words: lung cancer, adenomatous hyperplasia, multi-step progression, array-comparative genomic hybridization, chromosome abnormalities immunohistochemistry but the clonal association between $\mathrm{AAH}, \mathrm{BAC}$ and $\mathrm{AC}$ continue to be debated (1-7).

In the present study the array-comparative genomic hybridization (a-CGH) technique was applied on three DNA samples from a patient presenting $\mathrm{AAH}, \mathrm{BAC}$ and $\mathrm{AC}$ in one lung, in order to confirm the previous cytogenetic data for that patient (8), suggesting a clonal evolution of these lesions and the pre-neoplastic nature of AAH.

\section{Case report}

A 54-year-old female patient who had never smoked was diagnosed by CT scan at the Humanitas Clinical and Research Center (Milan, Italy) with a lung tumor in the upper right lobe and a GGO in the lower lobe, while the middle lobe appeared to be normal. Written informed consent was obtained from the patient. Histological evaluation lead to a diagnosis of $\mathrm{AC}$ with a BAC component in the upper right lobe, BAC in the inferior lobe and $\mathrm{AAH}$ in the middle lobe. Following pneumonectomy, a cytogenetic investigation of spontaneous metaphases obtained using a direct method from the three different samples was performed, as previously reported $(8,9)$. The karyotypes showed a clear clonal association among AC, $\mathrm{BAC}$ and $\mathrm{AAH}(8)$.

An a-CGH study was performed on the DNA isolated from the three lung samples and stored at $-20^{\circ} \mathrm{C}$ using the Qiagen DNeasy Blood \& Tissue kit (Qiagen Inc., Valencia, CA, USA). The samples were then processed using a SurePrint G3 Cancer CGH+SNP 4x180 K microarray kit (Agilent Technologies, Inc., Santa Clara, CA, USA) according to the manufacturer's instructions. Results were analyzed according to Human Genome version 19 (Hg19) (10). The data obtained from the a-CGH study confirmed the hypothesis of multistep progression of the lung cancer that was previously made on the basis of the previously reported, limited cytogenetic results (8). The three different lesions shared losses in 1p, 4p, 9q, 11p, 12p, 14q, 15q, 16p, 16q and 22q (Table I). The common minimal regions of deletions included genes with an established role in lung cancer that regulate the cell cycle or are involved in the maintenance of chromosomal stability and DNA repair (10-14). The most relevant genes included in the deleted regions are listed in Table I. The data obtained support the hypothesis suggested by Bettio et al concerning the loss of the cell cycle control 
Table I. Genetic aberrations detected using CGH and SNP microarray analysis in the AAH, BAC and AC samples with the most relevant genes involved in lung tumorigenesis and the percentage of altered cells.

\begin{tabular}{|c|c|c|c|c|c|}
\hline Chromosome imbalances & Size $(\mathrm{Mb})$ & Genes & $\mathrm{AAH}(\%)$ & $\mathrm{BAC}(\%)$ & $\mathrm{AC}(\%)$ \\
\hline $\operatorname{del}(1)(\mathrm{p} 32.3 \mathrm{p} 36.31)$ & 47.5 & $\begin{array}{l}\text { NBL1-EPHB2-RUNX3-MYCL1-RLF-STIL- } \\
\text { CDKN2C-ESP15-ERRFI1-YBX1-BMP8B- } \\
\text { COL9A2-PPT1-ZMPSTE24-PPIE-CAP1- } \\
\text { HEYL-HPCAL4-TRIT1-OXCT2-NT5C1A- } \\
\text { MFSD2-TMCO2-YRDC }\end{array}$ & 15 & 25 & 40 \\
\hline $\operatorname{del}(4)(\mathrm{p} 14)$ & 2.1 & - & 30 & 30 & 50 \\
\hline $\operatorname{del}(9)(q 31.3 q 32)$ & 2.0 & RGS3-POL3 & 20 & 50 & 70 \\
\hline $\operatorname{del}(11)(\mathrm{p} 15.4)$ & 1.9 & STK33-AKIP1-WEE1 & 25 & 25 & 30 \\
\hline $\operatorname{del}(12)(\mathrm{p} 11.21)$ & 1.8 & - & 30 & 25 & 50 \\
\hline $\operatorname{del}(14)(q 13.1 q 13.2)$ & 1.1 & SNX6 & 30 & 30 & 50 \\
\hline $\operatorname{del}(15)(q 15.1 q 21.1)$ & 5.7 & BUB1B-CASC5-TP53BP1 & 20 & 20 & 40 \\
\hline $\operatorname{del}(15)(\mathrm{q} 26.1)$ & 1.9 & CRTC3-MFGE8-IQGAP1-FANCI & 20 & 20 & 35 \\
\hline $\operatorname{del}(16)(\mathrm{p} 11.2)$ & 1.7 & - & 50 & 50 & 60 \\
\hline $\operatorname{del}(16)(q 21 q 22.2)$ & 9.0 & CBFB-CDH1 & 25 & 25 & 35 \\
\hline $\operatorname{del}(22)(\mathrm{q} 13.1 \mathrm{q} 13.2)$ & 2.7 & EP300 & 20 & 45 & 60 \\
\hline $\operatorname{dup}(1)(\mathrm{q} 23.1 \mathrm{q} 43)$ & 82.0 & $\begin{array}{l}\text { PRDX6-MUC1-PRCC-NTRK1-SDHC- } \\
\text { LAMC2-CD73-MDM4-PTPN14-TGFB2- } \\
\text { AKT3-ARNT-LAMB3 }\end{array}$ & - & 60 & 60 \\
\hline Trisomy 7 & 159.0 & $\begin{array}{l}\text { EGFR-DLX5-TWIST1-SEC61G- } \\
\text { VSTM2A-TAC1 }\end{array}$ & - & 30 & 70 \\
\hline Monosomy 9 & 139.3 & $\begin{array}{l}\text { CDKN2A-CDKN2B-TOPORS- } \\
\text { DMRTA1-JAK2-MTAP-XPA- } \\
\text { SET-FNBP1-NOTCH1 }\end{array}$ & - & 30 & 40 \\
\hline $\operatorname{del}(17)(\mathrm{q} 21.2 \mathrm{q} 21.33)$ & 9.2 & ETV4-NR1D1-RARA-TOP2A-BRCA1 & - & 20 & 35 \\
\hline Monosomy 22 & 50.9 & $\begin{array}{l}\text { NF2-CHEK2-SET5-SMARCB1- } \\
\text { EWSR1-ARHGAP8 }\end{array}$ & - & 30 & 40 \\
\hline $\operatorname{del}(12)(q 12 q 13.3)$ & 12.3 & WNT1-ATF1-CDK2-ERBB3 & - & - & 30 \\
\hline $\operatorname{del}(12)(\mathrm{q} 21.33 \mathrm{q} 24.32)$ & 34.1 & BTG1-PTPN11 & - & - & 30 \\
\hline $\operatorname{del}(16)(\mathrm{p} 11.2 \mathrm{pter})$ & 34.0 & $\begin{array}{l}\text { CIITA-SOCS1-TNRSF17-ABCC1- } \\
\text { PALB2-IL21R-FUS }\end{array}$ & - & - & 30 \\
\hline Monosomy 17 & 80.7 & TP53-NF1-TOP2A-HLF-ERBB2-SOX9-CBX2 & - & - & 30 \\
\hline Monosomy 19 & 58.6 & $\begin{array}{l}\text { STK11-CXCL17-CCNE1-C19orf12-LTBP4- } \\
\text { NUMBL-SPTBN4-ADCK4-ITPKC-SHKBP1 }\end{array}$ & - & - & 30 \\
\hline $\operatorname{del}(20)(\mathrm{p} 12 \mathrm{p} 13)$ & 4.0 & RASSF2 & - & - & 30 \\
\hline $\operatorname{del}(20)(q 12.2 q 13.33)$ & 23.7 & $\begin{array}{l}\text { E2F1-SRC-MYBL2-ZNF217-TOP1-CSE1L- } \\
\text { BCL2L1-TPX2 }\end{array}$ & - & - & 30 \\
\hline
\end{tabular}

CGH, compative genomic hybridization; SNP, single-nucleotide polymorphism; AAH, adenomatous hyperplasia; BAC, bronchoalveolar carcinoma; AC, adenocarcinoma; del, loss of one copy; dup, gain of one copy.

in the AAH sample in which actively replicating cells with a normal karyotype were observed (8).

In addition to the aforementioned abnormalities, the BAC and AC samples showed gain in 1q, loss in 17q, trisomy 7 , monosomy 9 and monosomy 22. Notably, these chromosome imbalances involved genes that have previously been demonstrated to play a crucial role in lung cancer (Table I) $(10,11,15-20)$.

Additional alterations were observed only in the AC specimen: Loss in 12q, 20p and 20q, loss of the entire 16p arm and chromosome 17 and 19 monosomy. These regions include genes reported to be frequently deleted in lung neoplasia (Table I) $(10,11,21-24)$.

\section{Discussion}

The pathogenesis of lung cancer and the criteria that regulate its progression are not well understood. Several studies have suggested that $\mathrm{AAH}$, frequently found in tissue surrounding lung $\mathrm{AC}$, may be a forerunner in its development but the genetic relationship between these two entities is not yet defined (4,25-27). The present case lends itself well to the investigation of the multistep carcinogenesis hypothesis of the lung because of the presence of three different lesions in the three lobes of the same lung. The a-CGH technique was applied in order to confirm the previous cytogenetic observations that were limited by the 
low proliferation rate of the tumor cells, and the poor resolution and incompleteness of metaphase spreads, which allowed the identification of only a few clonal aberrations. Moreover the a-CGH analysis allowed a more detailed characterization of the genomic imbalances present in the three lesions. The data appear to support the pre-neoplastic nature of the AAH lesion that presented several genetic alterations shared with the BAC and $\mathrm{AC}$ samples. The chromosomal regions showing recurring imbalances encompass genes with already demonstrated critical roles in lung cancer development and progression: Tumor suppressor genes, genes controlling the cell cycle, differentiation and apoptosis (10-24). The presence of chromosome abnormalities shared by all the samples and the increase in the number of rearrangements and percentage of altered cells from $\mathrm{AAH}$ through BAC to AC clearly correlate with a clonal evolution confirming the multi-step process in lung cancer.

\section{References}

1. Kitamura H, Kameda Y, Ito T and Hayashi H: Atypical adenomatous hyperplasia of the lung. Implications for the pathogenesis of peripheral lung adenocarcinoma. Am J Clin Pathol 111: 610-622, 1999.

2. Henschke CI, Yankelevitz DF, Mirtcheva R, McGuinness G, McCauley D and Miettinen OS; ELCAP Group: CT screening for lung cancer: Frequency and significance of part-solid and nonsolid nodules. AJR Am J Roentgenol 178: 1053-1057, 2002.

3. Nakata M, Saeki H, Takata I, Segawa Y, Mogami H, Mandai K and Eguchi K: Focal ground-glass opacity detected by low-dose helical CT. Chest 121: 1464-1467, 2002.

4. Morandi L, Asioli S, Cavazza A, Pession A and Damiani S: Genetic relationship among atypical adenomatous hyperplasia, bronchioloalveolar carcinoma and adenocarcinoma of the lung. Lung Cancer 56: 35-42, 2007.

5. Kerr KM, Carey FA, King G and Lamb D: Atypical alveolar hyperplasia: Relationship with pulmonary adenocarcinoma, p53, and c-erbB-2 expression. J Pathol 174: 249-256, 1994.

6. Tomida S, Yatabe Y, Yanagisawa K, Mitsudomi T and Takahashi T: Throwing new light on lung cancer pathogenesis: Updates on three recent topics. Cancer Sci 96: 63-68, 2005.

7. Sano T, Kitayama Y, Igarashi H, Suzuki M, Tanioka F, Chida K, Okudela K and Sugimura H: Chromosomal numerical abnormalities in early stage lung adenocarcinoma. Pathol Int 56: $117-125,2006$

8. Bettio D, Cariboni U, Venci A, Valente M, Spaggiari P and Alloisio M: Cytogenetic findings in lung cancer that illuminate its biological history from adenomatous hyperplasia to bronchioalveolar carcinoma to adenocarcinoma: A case report. Exp Ther Med 4: 1032-1034, 2012.

9. Bettio D, Rizzi N, Giardino D, Persani L, Pecori-Giraldi F, Losa M and Larizza L: Cytogenetic study of pituitary adenomas. Cancer Genet Cytogenet 98: 131-136, 1997.

10. Genome Bioinformatics Group of University of California Santa Cruz: UCSC genome browser. http://genome.ucsc.edu/cgi-bin/ hgGateway (accessed on November 14, 2014).

11. Heighway J and Betticher DC: Lung: Non-small cell carcinoma. In: Atlas of Genetics and Cytogenetics in Oncology and Haematology. http://atlasgeneticsoncology.org/Tumors/LungNonSmallCellID5141.html (Accessed November 4, 2014).
12. Demopoulos K, Arvanitis DA, Vassilakis DA, Siafakas NM and Spandidos DA: MYCL1, FHIT, SPARC, p16 (INK4) and TP53 genes associated to lung cancer in idiopathic pulmonary fibrosis. J Cell Mol Med 6: 215-222, 2002.

13. Li MY, Lai PL, Chou YT, Chi AP, Mi YZ, Khoo KH, Chang GD, Wu CW, Meng TC and Chen GC: Protein tyrosine phosphatase PTPN3 inhibits lung cancer cell proliferation and migration by promoting EGFR endocytic degradation. Oncogene 34: 3791-3803, 2015.

14. Liu X, Su L and Liu X: Loss of CDH1 up-regulates epidermal growth factor receptor via phosphorylation of YBX1 in non-small cell lung cancer cells. FEBS Lett 587: 3995-4000, 2013.

15. Yun HM, Park KR, Lee HP, Lee DH, Jo M, Shin DH, Yoon DY, Han SB and Hong JT: PRDX6 promotes lung tumor progression via its GPx and iPLA2 activities. Free Radic Biol Med 69: 367-376, 2014.

16. Testa JR and Siegfried JM: Chromosome abnormalities in human non-small cell lung cancer. Cancer Res 52 (9 Suppl): 2702s-2706s, 1992.

17. Li J, Bi L, Sun Y, Lu Z, Lin Y, Bai O and Shao H: Text mining and network analysis of molecular interaction in non-small cell lung cancer by using natural language processing. Mol Biol Rep 41: 8071-8079, 2014.

18. Panani AD, Maliaga K, Babanaraki A and Bellenis I: Numerical abnormalities of chromosome 9 and p16CDKN2A gene deletion detected by FISH in non-small cell lung cancer. Anticancer Res 29: 4483-4487, 2009.

19. Oyanagi H, Takenaka K, Ishikawa S, Kawano Y, Adachi Y, Ueda K, Wada $\mathrm{H}$ and Tanaka F: Expression of LUN gene that encodes a novel RING finger protein is correlated with development and progression of non-small cell lung cancer. Lung Cancer 46: 21-28, 2004.

20. Meng X, Lu P, Bai H, Xiao P and Fan Q: Transcriptional regulatory networks in human lung adenocarcinoma. Mol Med Rep 6: 961-966, 2012.

21. Testa JR, Liu Z, Feder M, Bell DW, Balsara B, Cheng JQ and Taguchi T: Advances in the analysis of chromosome alterations in human lung carcinomas. Cancer Genet Cytogenet 95: 20-32, 1997.

22. González-Sánchez E, Martín-Caballero J, Flores JM, Hernández-Losa J, Ma Ángeles Montero, Cortés J, Mares R, Barbacid M and Recio JA: Lkb1 loss promotes tumor progression of BRAF (V600E)-induced lung adenomas. PLoS One 8: e66933, 2013.

23. Clark J, Freeman J and Donninger H: Loss of RASSF2 enhances tumorigencity of lung cancer cells and confers resistance to chemotherapy. Mol Biol Int 2012: 705948, 2012.

24. Papay J, Krenacs T, Moldvay J, Stelkovics E, Furak J, Molnar B and Kopper L: Immunophenotypic profiling of nonsmall cell lung cancer progression using the tissue microarray approach. Appl Immunohistochem Mol Morphol 15: 19-30, 2007.

25. Kitaguchi S, Takeshima Y, Nishisaka T and Inai K: Proliferative activity, p53 expression and loss of heterozygosity on $3 p, 9 p$ and $17 \mathrm{p}$ in atypical adenomatous hyperplasia of the lung. Hiroshima J Med Sci 47: 17-25, 1998

26. Kohno H, Hiroshima K, Toyozaki T, Fujisawa T and Ohwada H: p53 mutation and allelic loss of chromosome 3p, 9p of preneoplastic lesions in patients with nonsmall cell lung carcinoma. Cancer 85: 341-347, 1999.

27. Yamasaki M, Takeshima Y, Fujii S, Kitaguchi S, Matsuura M, Tagawa K and Inai K: Correlation between genetic alterations and histopathological subtypes in bronchiolo-alveolar carcinoma and atypical adenomatous hyperplasia of the lung. Pathol Int 50: 778-785, 2000 